\title{
Dynamics of offshore wind turbines supported on two foundations
}

1 Subhamoy Bhattacharya $\mathrm{PhD}$ (Cantab) Senior Lecturer in Dynamics, University of Bristol, Bristol, UK

2 James A. Cox MEng

Research Postgraduate Student, University of Bristol, Bristol, UK
3 Domenico Lombardi MSC

Research Postgraduate Student, University of Bristol, Bristol, UK

4 David Muir Wood MA, PhD(Cantab), FICE, FREng Emeritus Professor of Civil Engineering, University of Bristol, Bristol, UK
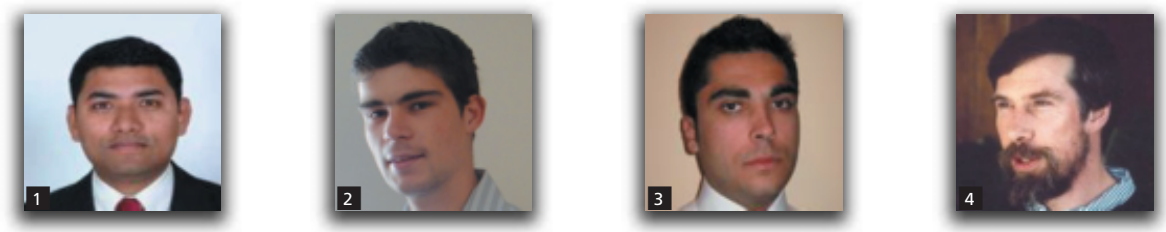

Offshore wind turbines are currently considered as a reliable source of renewable energy in the UK. These structures, owing to their slender nature, are dynamically sensitive at low frequencies, the first modal frequency of the system (less than $1 \mathrm{~Hz}$ ) being very close to that of the excitation frequencies. The majority of operational offshore wind turbines situated in UK waters are founded on monopiles in water depths up to $30 \mathrm{~m}$. For future development rounds where water depths are up to $70 \mathrm{~m}$, alternative foundation arrangements are needed. To date there have been no long-term observations of the performance of these relatively novel structures. Monitoring of a limited number of offshore wind turbines has indicated a departure of the system dynamics from the design requirements. This paper summarises the results from a series of 1:100 scale tests of a V120 Vestas turbine supported on two types of foundation: monopiles and tetrapod suction caissons. The test bed used consisted of kaolin clay and sand. Up to 1.25 million loading cycles were applied to the scaled model, and the dynamic properties of the system were monitored. The results provide an insight into the long-term performance. Some interesting dynamic soil-structure interaction issues are identified and discussed.

\section{Notation}

D pile diameter

$D_{\text {sp }} \quad$ median sediment grain diameter

$E \quad$ Young's modulus of pile

EI pile bending stiffness

$e_{\max }$ maximum void ratio

$e_{\text {min }}$ minimum void ratio

$f_{\mathrm{f}} \quad$ forcing frequency

$f_{\mathrm{n}} \quad$ system frequency

$G \quad$ shear modulus of soil at reference depth

$G_{\mathrm{s}} \quad$ specific gravity of solids

$K_{\mathrm{h}} \quad$ horizontal permeability of soil

$K_{1} \quad$ lateral foundation stiffness

$L \quad$ length of tower

$M \quad$ mass of rotor and blades

$N \quad$ number of cycles

$P \quad$ total lateral load on wind turbine

$t_{\mathrm{w}} \quad$ thickness of pile

y lateral pile head deflection

$y_{\mathrm{c}} \quad$ point of application of total load

$\sigma_{\mathrm{y}} \quad$ yield stress of pile material

$\psi_{\text {crit }}$ critical angle of friction

\section{Introduction}

With the current demand for clean 'green energy' there are very strong economic incentives to construct offshore wind farms. The rate of expansion of offshore wind energy is soon predicted to outstrip even levels seen during the heyday of the offshore oil and gas industry, and as a result substantial effort has been put into research and development. The UK offshore wind sector has been steadily expanding under the direction of the government. So far, planning has been conducted in so-called 'rounds'. Each of these rounds has allowed applications to be submitted for a number of wind farms in the coastal waters surrounding the UK; applications for the third round have recently been completed.

(a) Round 1. The first round of offshore development saw the submission of 12 proposals for offshore wind schemes, with output expected to be in the region of $1.4 \mathrm{GW}$. For these schemes the water depths are never greater than $20 \mathrm{~m}$, and no site is further than $13 \mathrm{~km}$ from the shore. All sites, with one exception, make use of monopile foundations.

(b) Round 2. The second round contains some 14 sites, plus their associated expansions (recent additions). Output is expected to be $7 \cdot 3 \mathrm{GW}$. Round 2 sites are situated in more adverse 
water conditions with a maximum depth of $37 \mathrm{~m}$, with the furthest site being $40 \mathrm{~km}$ from shore. As with the round 1 turbines, the water is sufficiently shallow that most of the foundations have been designed as monopiles.

(c) Round 3. The third round represents a large expansion in Britain's renewable energy sector, with a total output estimated to be in the region of $21 \mathrm{GW}$. Water depths are expected to range up to $70 \mathrm{~m}$, and some sites are located up to $210 \mathrm{~km}$ offshore. For such developments in deep water alternative foundation arrangements are required, as monopile structures start to become uneconomical, owing to the size of pile required. As part of the Carbon Trust's Offshore Wind Accelerator various alternative arrangements have been proposed, such as four-legged jackets, tripods, gravity foundations, floating platforms and suction caissons. As most round 3 sites are still in the design stages, the foundation arrangements are unknown; however, it is expected that monopiles will no longer be sufficient.

\subsection{Aim and scope of the paper}

With each successive round of offshore wind farm expansion, the trend has been for developments to be in regions further offshore, in areas where the water depth is greater. This presents some unique engineering challenges, as the dynamic behaviour of these structures will be heavily dependent upon foundation type selection and soil conditions at the site. The aim of the paper is therefore to

(a) highlight the design issues related to dynamic soil-structure interaction of offshore wind turbines

(b) summarise the preliminary test results obtained from a 1:100 scale model wind turbine supported on two types of foundation: (a) monopile; $(b)$ tetrapod suction caisson. The tests were carried out in BLADE (Bristol Laboratory for Advanced Dynamics Engineering) where dynamic soilstructure interaction characteristics were explored.

\section{Dynamic considerations for designing offshore wind turbines}

Offshore wind turbines are particularly sensitive to dynamic loading conditions because of the combination of the slender structural nature of the turbine and the wide range of cyclic loads to which the turbine is subjected. Figure 1 shows a summary of the typical forcing frequencies applied to a Vestas V120 4.5 MW wind turbine system: the $1 \mathrm{P}$ frequency signifies the rotational frequency of the turbine, and the $3 \mathrm{P}$ frequency signifies the blade-passing frequency. The $3 \mathrm{P}$ frequency results from shadowing effects of the blade on the tower caused by a drop in the upstream wind velocity in the vicinity of the tower as each of the three blades passes in front of the tower. An example of the dynamic wind loading is also shown in Figure 1, utilising the Frøya wind spectrum (Andersen and Løvseth, 2006). In addition, the dynamic wave loads are modelled using the Pierson and Moskowitz (1964) spectrum, which is considered appropriate for UK North Sea locations. In order for turbines to remain unconditionally stable, and avoid unplanned resonance effects, they have to be designed in such a way that the magnitude of the dynamic load applied to them can be minimised.

To do this, one of three design methods can be used to place the first modal (natural) frequency of the system (structure-foundation

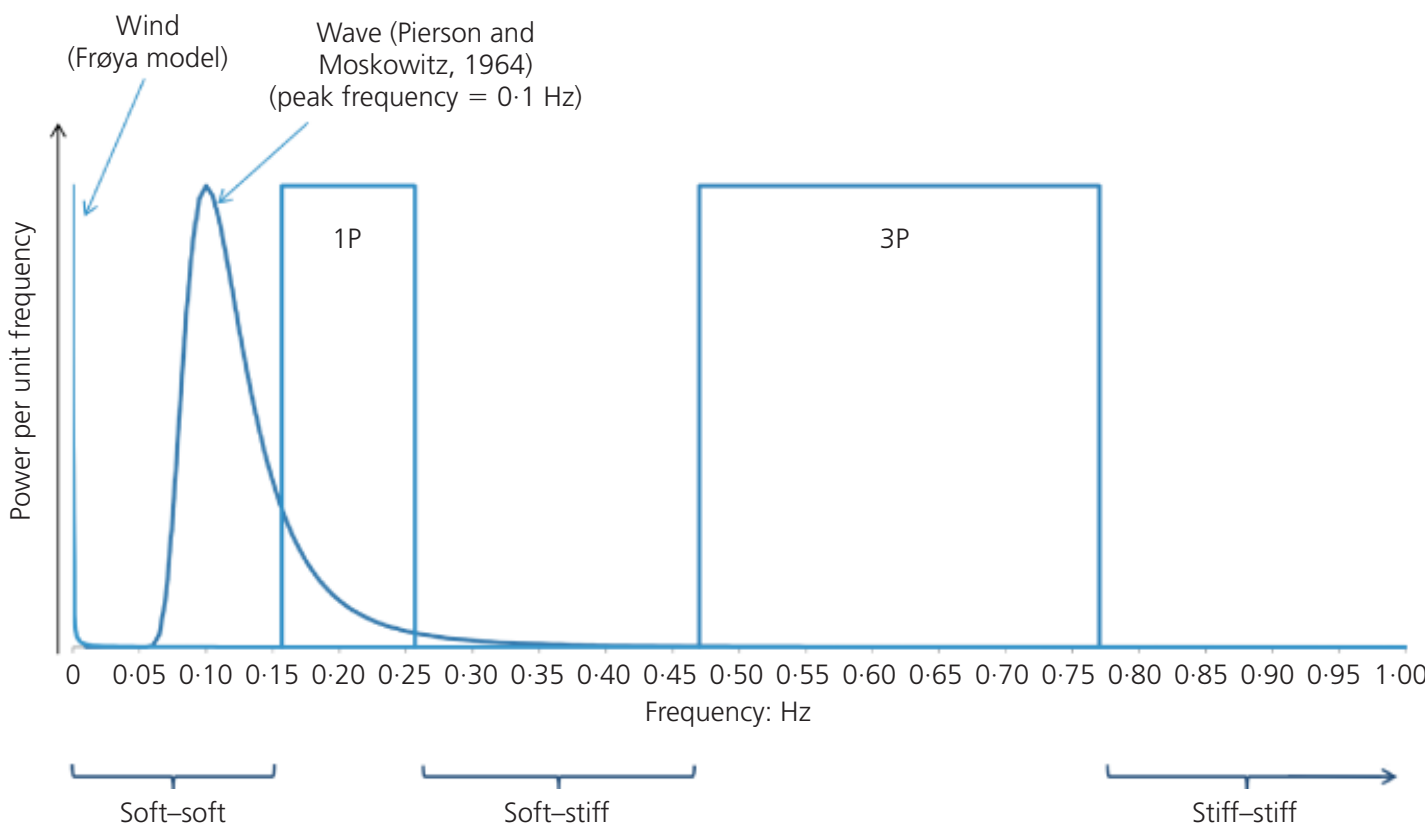

Figure 1. Forcing frequencies plotted against power spectral density for Vestas V120 4.5 MW wind turbine 
combination) in either the 'soft-soft', 'soft-stiff' or 'stiff-stiff' regions, as shown in Figure 1. Typically, most turbines supported on monopiles are designed to be 'soft-stiff', as the support structure (foundation and transition piece) can have a greater flexibility, reducing the costs associated with the additional material required. The frequencies of particular interest are those in the region from $0.01 \mathrm{~Hz}$ to $1 \mathrm{~Hz}$, as this is the region within which the first modal frequency of a wind turbine will lie. As discussed, within this critical band various exciting forces exist, which makes the system dynamically sensitive. Table 1 summarises the first natural frequencies of five offshore wind turbines, either operational or currently being built. If the values of the natural frequency of the wind turbine system are compared with Figure 1, it becomes very apparent that these structures are potentially very dynamically sensitive.

Monitoring of a limited number of installed wind turbines has indicated a departure of the overall system dynamics from the design assumptions. For example, at Lely (Netherlands), the natural frequency following 6 months of operation was $0.63 \mathrm{~Hz}$, compared with a design frequency of $0.41 \mathrm{~Hz}$ (Kühn, 2000; Zaaijer, 2006). From Figure 1, it is clear that any shift of the natural frequency of the system may coincide with the forcing frequencies, causing unplanned resonance effects and leading to rapid wear and tear of the onboard machinery and enhanced deflections. In extreme cases, this may lead to failure. So far, no explanation has been offered for such a change in the structural natural frequency; however, theories relating to cyclic strain accumulation (sandy soil) and pore water accumulation (clay) have been proposed. As turbines increase in size and power, so do the associated loads. In order to maintain serviceability limits, the dynamic soil-structure interactions need to be quantified; at present these issues are not well understood.

\section{Long-term performance of monopile- supported wind turbines}

In order to understand the effects of long-term cyclic loading on a monopile-supported wind turbine, a series of 1:100 scale model tests were conducted. Scaling laws were derived so that the test results can be plotted using non-dimensional groups, which can later be scaled up to a full-size prototype system. These scaling laws are listed in Table 2; details of their derivation can be found in Bhattacharya et al. (2011). Despite the scientific rigour, the experimental investigation had some limitations: only a homogeneous isotropic medium was considered at this stage; the soil stiffness was low, and was based on maintaining a representative strain field alone; the dynamic load case considered only mean operational conditions; and damping was not considered in detail.

Figure 2(a) shows a schematic diagram of the wind turbine supported on a monopile, and Table 3 details the wind turbine model parameters. To provide an initial reference point, the fixed base frequency of the turbine was assessed; this was accomplished by clamping the bottom of the tower to a rigid bench, and conducting a snap-back test. The fixed base frequency was measured to be around $10 \cdot 27 \mathrm{~Hz}$. To test whether the natural frequency changed over time, the turbine system was carefully installed in the soil test bed (detailed below), and the dynamic properties of the model were then assessed by a snap-back test. The system was then subjected to a period of representative dynamic loading: the load was applied using an actuator (replicat-

$\begin{array}{ccc}\text { Project and reference } \quad \text { Soil profile } & \text { First natural } \\ \text { frequency of } & \text { Remarks } \\ & \text { system: } \mathrm{Hz}\end{array}$

North Hoyle: Irish sea - $\quad$ Upper seabed layers comprise variations

Liverpool Bay

(Vestas V80 - 2.0 MW)

of sand and clay layers. Below is weak

Lely (A2) - inland sea,

ljsselmeer (the

Netherlands)

(Nedwind 500 kW/41)

Irene Vorrink - inland

sea, ljsselmeer (the

Netherlands)

(Nordtank NTK600/43)

Kentish Flat

(Vestas V90 - 3.0 MW)

Frederikshavn

(Vestas V90 - 3.0 MW)

rock (mudstone or sandstone).

Pile passes through soft layer to stiffer sandy layer.

Pile passes through soft layer to stiffer sandy layer.

Soil at site is layered with seabed sand underlain by soft to firm clay on top of London Clay formation.

Suction caisson founded in a fine sand bed.
Frequency measured and reported in Zaaijer (2006)

0.345 Frequency prediction based on Adhikari and Bhattacharya (2012). Details of wind farm can be found in Carter (2007)

0.634 Frequency measured and reported in Zaaijer (2006)

0.38 Frequency prediction based on Adhikari and Bhattacharya (2012)

0.30 Frequency extracted from Houlsby et al. (2005)

Table 1. First natural frequency of some operational

monopile-supported wind turbines 


\begin{tabular}{lll}
$\begin{array}{l}\text { Name of non- } \\
\text { dimensional group }\end{array}$ & Physical meaning & Remarks \\
\hline$\frac{P}{G D^{2}}$ & $\begin{array}{l}\text { Average strain field in the soil around the pile and cyclic stress ratio } \\
\text { (CSR) in the shear zone (i.e. ratio of shear stress to vertical effective } \\
\text { stress at a particular depth) }\end{array}$ & $\begin{array}{l}\text { Similar strain field, which will } \\
\text { control the degradation of soil } \\
\text { stiffness }\end{array}$ \\
$\frac{k_{\mathrm{h}}}{f_{\mathrm{f}} D}$ & Rate of application of lateral loading to the model & $\begin{array}{l}\text { Modelling consolidation and the } \\
\text { dissipation of pore water pressure }\end{array}$ \\
$\frac{f_{\mathrm{f}}}{f_{\mathrm{n}}}$ & Relative spacing of forcing frequencies and natural frequencies & System dynamics \\
$\frac{P y}{E D^{2} t_{\mathrm{w}}}$ & Bending strain in pile & Non-linearity in material of pile \\
$\frac{P y}{\sigma_{\mathrm{y}} D^{2} t_{\mathrm{w}}}$ & Stress level in pile & Fatigue limit state
\end{tabular}

Table 2. Scaling laws for studying monopile-supported wind turbines

ing 3P loading) and a motor turning the turbine blades (replicating 1P loading). This loading regime was applied for a particular time interval (or a certain number of cycles); the natural frequency was then re-measured by conducting a snap-back test. During this snap-back test, the actuator was disconnected from the tower, and the tower was given a small impulse displacement; the resulting acceleration decay of the system was recorded.

The tests were carried out in dry sand, saturated sand, and soft overconsolidated kaolin clay. Details of the sample preparation, set-up and testing procedure can be found in Bhattacharya et al. (2011). A sensitivity study was carried out with three different forcing frequencies (3P loading denoted by $f_{\mathrm{f}}$ in Table 2 ) of $2 \mathrm{~Hz}$, $20 \mathrm{~Hz}$ and $125 \mathrm{~Hz}$, applied by the electro-dynamic actuator. The dynamic influence of these frequencies is illustrated in Figure 3. The 1P frequency of $0.66 \mathrm{~Hz}$ representing the rotor frequency was applied by an electric motor powered by a DC supply.

Figure 4 shows data from a typical snap-back test obtained from the monopile-supported wind turbine founded in sand. The test results are plotted in the frequency domain using the Welch (1967) method. The system has a dominant frequency of about $3 \cdot 3 \mathrm{~Hz}$; the foundation provides significant flexibility to the wind turbine system, which had a fixed base frequency of $10 \cdot 27 \mathrm{~Hz}$. The $f_{\mathrm{f}} / f_{\mathrm{n}}$ ratio was varied between 0.6 and 44 in the series of model tests.

In a series of additional tests, the stiffness of the foundation alone under cyclic loading was also measured, utilising the set-up shown in Figure 2(b) with the superstructure not attached to the foundation. The pile was subjected to 5000 cycles of loading, and then a pushover force was applied to obtain a load-displacement relationship. The tests were repeated after 10000 cycles, and the new stiffness was compared with the initial static stiffness. These tests were carried out to verify whether or not the change in foundation stiffness alone would be adequate to predict the change in natural frequency of the system.
The following summarises the main conclusions.

(a) Wind turbines founded in sands (both dry and saturated) exhibited near-field soil stiffening, resulting in an increase in frequency, possibly as a result of densification. The results in sand are very similar to the observations carried out by Leblanc et al. (2010) on a cyclically loaded pile, where it was observed that, as a result of cyclic loading, the stiffness of the monopile increased. In comparison, when founded in clay (Figure 5), the foundation degraded, causing a reduction in the frequency with the number of cycles. This frequency drop appears to be a function of the soil strain level $\left(P / G D^{2}\right)$ and the number of loading cycles.

(b) Under certain conditions, cyclic loading may have a negative effect on monopile-supported wind turbines founded in clayey soil, as the foundation stiffness and system natural frequency will exhibit a continued decrease over time. The conditions under which such degradation will occur relate to functions of: (i) strain level in the soil imposed by the monopile; and (ii) the $f_{\mathrm{f}} / f_{\mathrm{n}}$ parameter, the relative value of the system frequency in comparison with the forcing frequency.

(c) From the test results obtained, it can be seen that the greater the strain level in the soil (the $\left(P / G D^{2}\right)$ term in Table 2), the greater is the degradation observed. As a result, in practice, large-diameter piles present a better solution than smalldiameter piles. For example, for a particular ground condition (fixed shear modulus $G$ ) and a particular turbine at a site where the total lateral load $(P)$ is constant, the larger the monopile diameter, the lower is the strain level, and consequently the lower is the degradation.

(d) Using the pile-head displacement test results (presented in Figure 6), a prediction of the frequency change of the overall system was made. For the purposes of numerical analysis, the foundation can be replaced by three springs, as shown in Figure 7: $K_{\mathrm{L}}$ (lateral spring); $K_{\mathrm{R}}$ (rotational spring) and $K_{\mathrm{V}}$ (vertical spring) (Adhikari and Bhattacharya, 2011, 2012). 


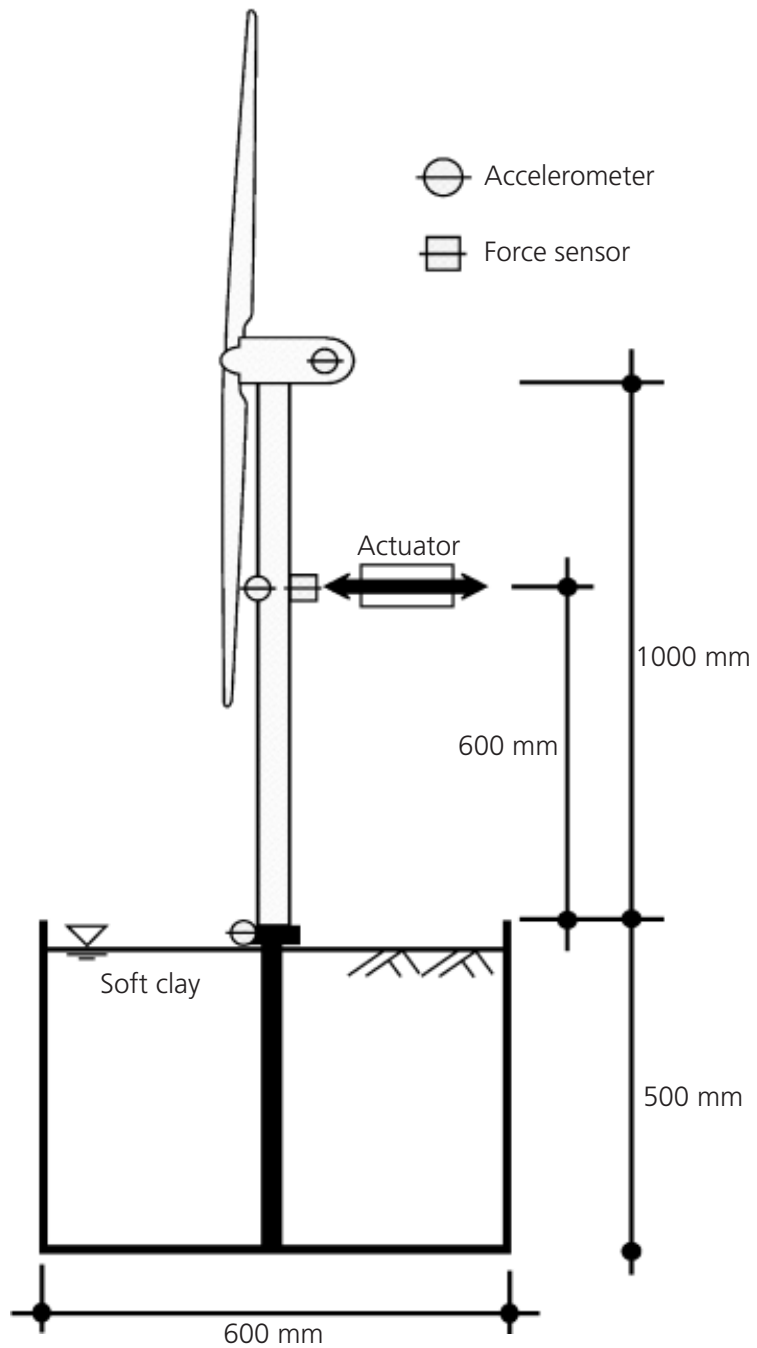

(a)

Accelerometer

Force senso

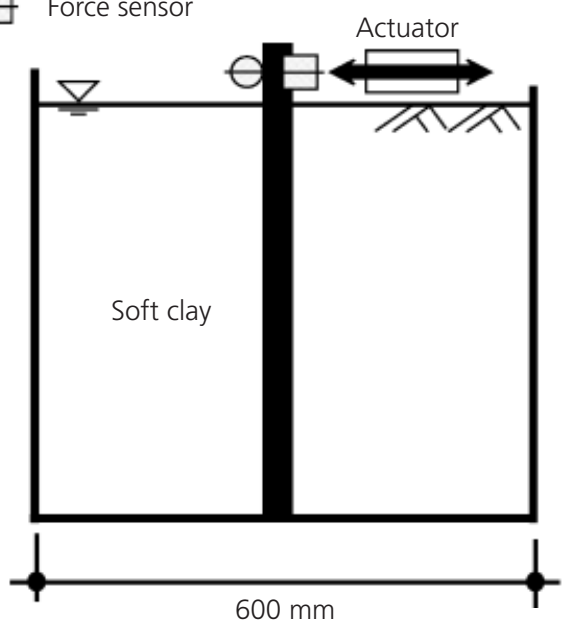

(b)

Figure 2. (a) Experimental set-up of wind turbine supported on monopile; (b) set-up for studying foundation stiffness degradation
This foundation spring analogy model is currently being used in industry-standard software such as Bladed (2008). Table 4 shows the prediction of the system frequency based on the results obtained from the pile-head displacement tests (considering the monopile alone), and compares this with the observed values of the system frequency under similar cycles of loading. From the data presented in Table 4 it can be seen that the mathematical model based on the foundation stiffness degradation alone overpredicts the measured frequency change of the system, indicating that the foundation-only degradation model cannot fully capture the dynamic soilstructure interaction effects. This may be due to the lack of feedback mechanisms between superstructure and the foundations, such as damping. Further to this, it may be inferred that the dynamic response of the system is nonlinear. Further study is required to characterise these aspects.

\section{Long-term performance of wind turbines supported by tetrapod suction caissons}

Suction caissons have been widely used in the oil and gas industry for both jack-up and permanent platforms, such as the SPT/Heerema Centrica and Draupner E platforms (Ibsen and Brincker, 2004). Suction caissons have the significant advantage over conventional foundations of being quick to install and easy to remove. A suction caisson is effectively an upturned bucket embedded in the seabed, initially by its self-weight and subsequently by an induced negative pressure inside the caisson, drawing it into the seabed. Bye et al. (1995) first proposed the use of suction caissons as foundations for offshore wind turbines. So far, only a single wind turbine has been constructed on a single suction caisson; this was sited at Fredrickshaven, and is the property of Aalborg University. At present, information is limited, as it is the focus of ongoing research (Houlsby et al., 2005).

Using the derived scaling laws, a 1:100 scale model of an offshore wind turbine supported by a tetrapod suction caisson was created. For the purposes of design it was assumed that a Vestas V120 4.5 MW turbine would be modelled (representing the larger type of turbine that would be used in round 3 of offshore wind expansion). The model caissons were $7.4 \mathrm{~cm}$ in diameter and $5.5 \mathrm{~cm}$ deep, and were spaced $40 \mathrm{~cm}$ apart in orthogonal directions; this design was based upon design recommendations by Byrne and Houlsby (2003) (Figures 8(a), 8(b) and 9). In order to test the long-term dynamic response of the suction caissons, the model was founded in a representative sand matrix with properties as described in Table 5. However, the installation of the foundation was not studied.

For this series of tests two types of sand were used, as follows.

(a) Leighton Buzzard fraction E (LED) sand (uniform graded fine silica sand having $D_{50}$ of $0.14 \mathrm{~mm}$ ) poured to $28 \%$ relative density. The average shear modulus of the soil at the mid-depth of the foundation is estimated to be $4 \cdot 3 \mathrm{MPa}$. 


\begin{tabular}{|c|c|}
\hline Parameters & Values \\
\hline Bending stiffness of tower, El: $\mathrm{Nmm}^{2}$ & $2.125 \times 10^{9}$ \\
\hline Mass of rotor and blades, $M$ : kg & $1 \cdot 348$ \\
\hline Length of tower, $L: m$ & $1 \cdot 0$ \\
\hline Mass per unit length of tower: $\mathrm{kg} / \mathrm{m}$ & 0.576 \\
\hline Frequency of system fixed at base of tower: $\mathrm{Hz}$ & $10 \cdot 27$ \\
\hline
\end{tabular}

Remarks

Pile length: $m$

El (pile): $\mathrm{N} \mathrm{mm}^{2}$

Soils used: (a) Leighton Buzzard fraction E sand; (b) Kaolin clay; (c) mixture of Leighton Buzzard fraction $\mathrm{E}$ and Leighton Buzzard fraction $\mathrm{B}$ sand
0.5

$3.18 \times 10^{8}$

For kaolin clay, shear modulus Details of the sands are given in Table 5 $G$ was measured as $6 \mathrm{MPa}$ using bender elements

\section{Bending rigidity of tower \\ Motor weighs $1.008 \mathrm{~kg}$ and blades $0.34 \mathrm{~kg}$ \\ Aluminium tube $38 \mathrm{~mm}$ in diameter and $1.6 \mathrm{~mm}$ thick \\ Uniform tube \\ Measured value. Predicted value based on a single-degree-of-freedom model (Figure 7) is $10.66 \mathrm{~Hz}$ \\ Data not directly relevant in this paper; provided for completeness}

Table 3. Details of model wind turbine

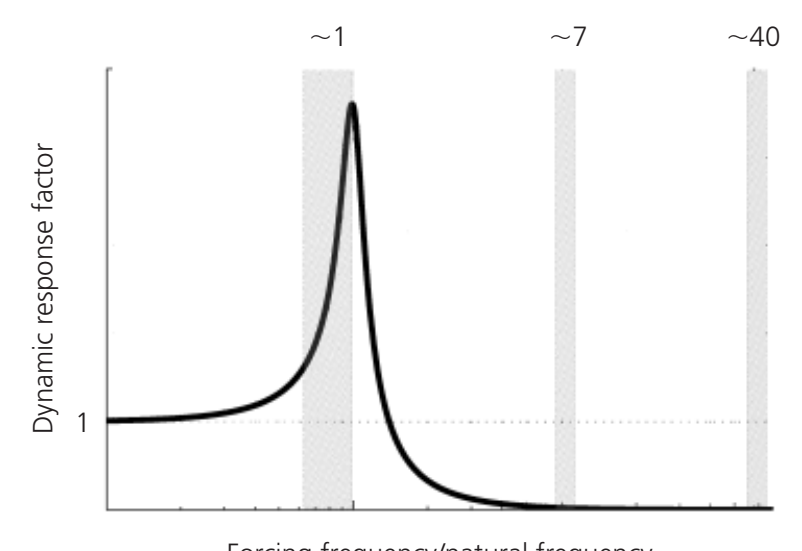

Forcing frequency/natural frequency

Figure 3. Magnitude of dynamic influence

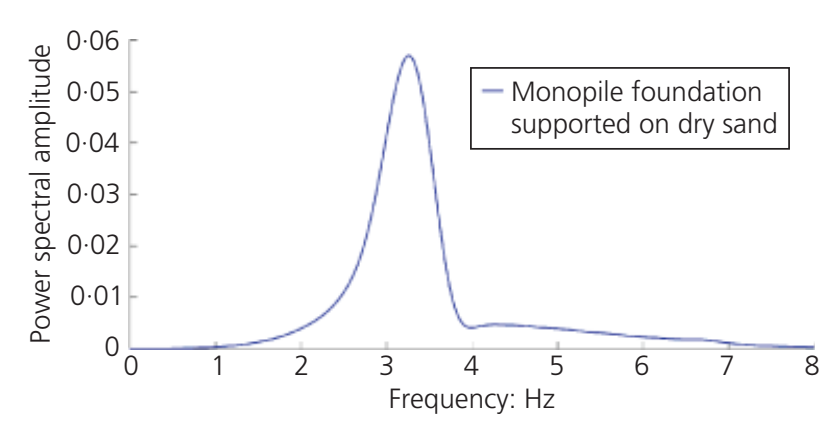

Figure 4. Typical test result from snap-back test on monopilesupported wind turbine model, plotted in frequency domain (b) A mixture of Leighton Buzzard fraction B and Leighton Buzzard fraction E (LBED) sand was employed to model a relatively stiff soil configuration. The mean diameter ratio between the two fractions of sands $\left(D_{50 \text {-Fraction-B }}\right.$

$D_{50 \text {-Fraction-E }} \approx 6$ ) was considered beneficial for an increase of packing when the two types of particles were mixed together. The fine particles were expected to fill the voids efficiently in the large-particle matrix. The mass composition corresponding to the theoretical maximum packing density of the mixture was calculated according to a classic model of packing (German, 1989), resulting in

$X_{\text {FractionB }}: X_{\text {FractionE }}=85: 15$. The sand mix had an approximate relative density of $2 \%$, and the average shear modulus at the mid-depth of the foundation was estimated to be about 6.6 MPa.

The shear modulus of the two sand specimens was calculated using the method proposed by Hardin and Drnevich (1972). These calculated values matched within $10 \%$ of the shear modulus measurements carried out on this specimen in the Blade laboratories during the Reluis project; see Dihoru et al. (2010). The test bed was prepared by standard air-pluviation of the sand, after which the model was carefully installed under a steady vertical load. The model was then subjected to the testing regime described previously.

Figure 10 shows a typical frequency response of the wind turbine system supported on a tetrapod foundation (Figure 8(b)). The plot reveals a distinct difference when compared with the similar response from a monopile (Figure 4), in that two closely spaced response peaks were observed. The two closely spaced natural frequencies correspond to modes of tower vibration in orthogonal 


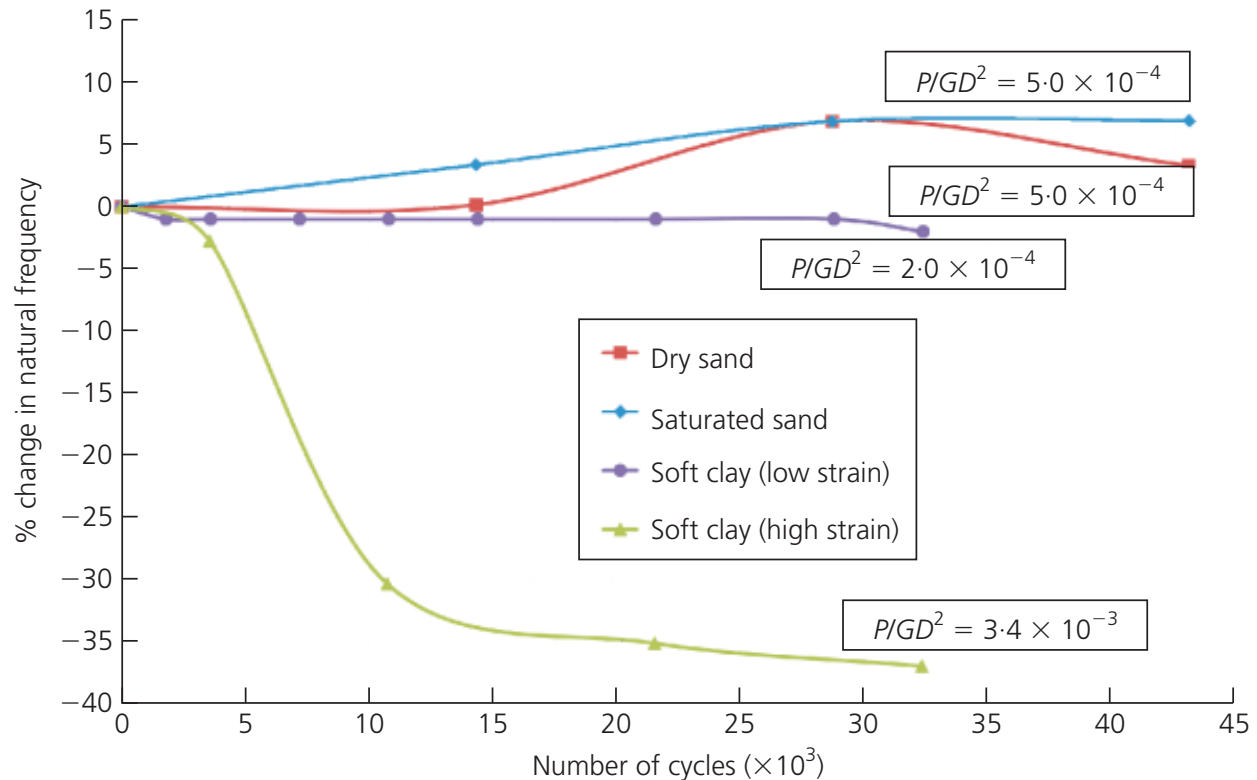

Figure 5. Simplified plot showing change in frequency for dry sand, saturated sand and clay

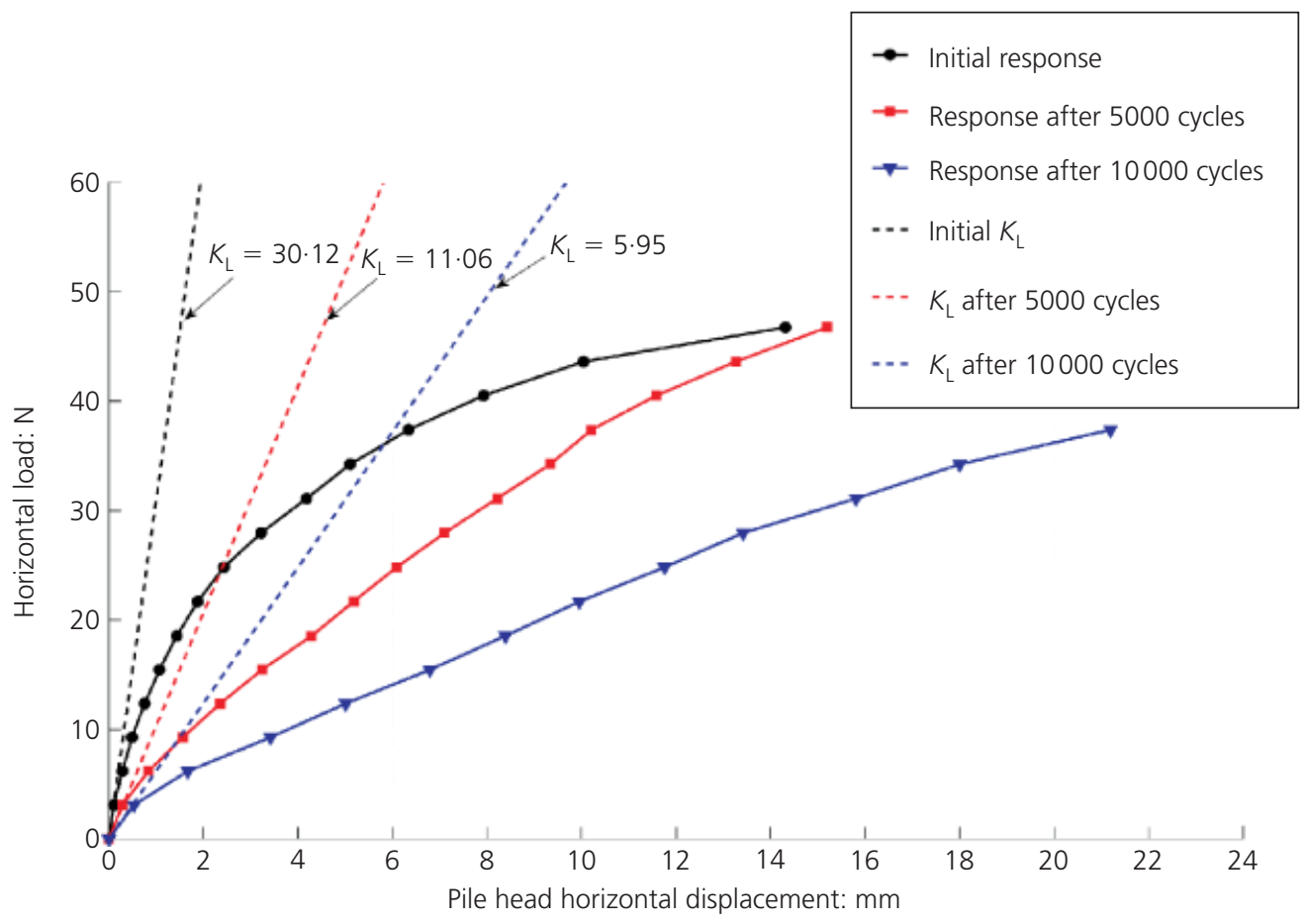

Figure 6. Foundation stiffness degradation in clay

horizontal directions. To gain a better understanding of the observed results, the model system was replicated in SAP 2000, and the dynamics were calibrated. From this computer model it was found that different vertical stiffness between individual caissons could produce the secondary modes recorded. In addi- tion, as expected, the foundation provides additional flexibility to the structure.

The change in natural frequency of the system due to cyclic loading is shown in Figure 11 for two types of soil for a constant 


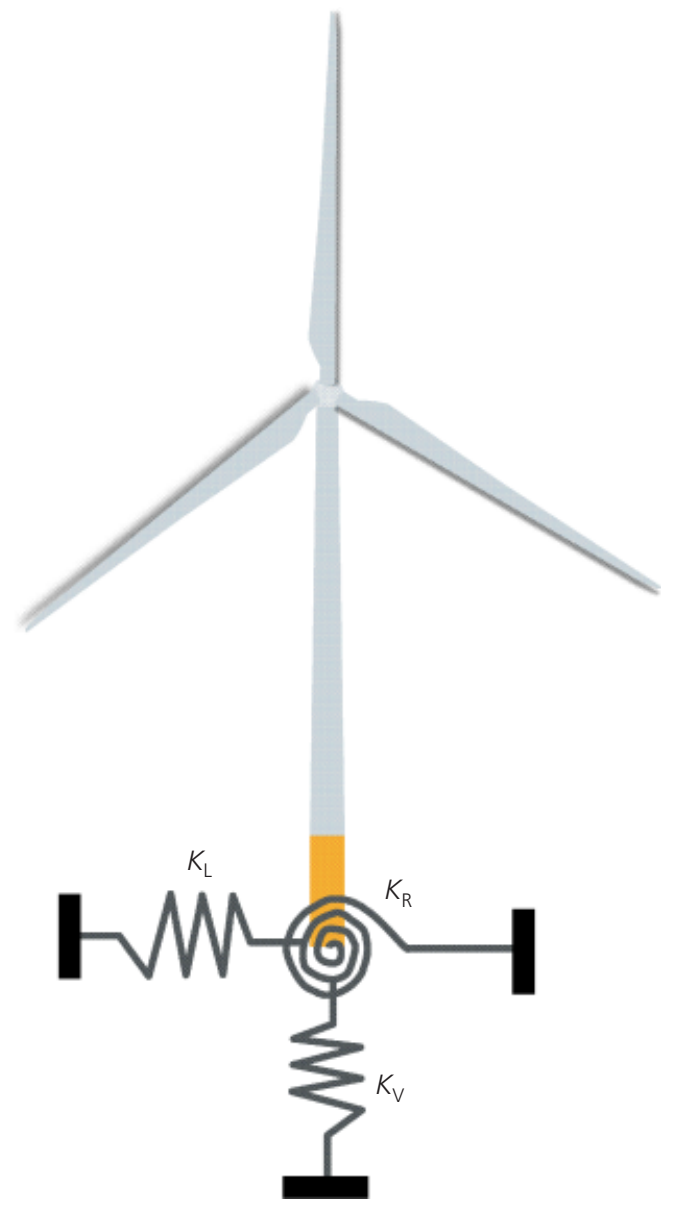

Figure 7. Simplified structural model

$\left(F / G D^{2}\right)$, which corresponds to a particular strain level very similar to the parameter $\left(P / G D^{2}\right)$ for monopiles. The definition of $\left(F / G D^{2}\right)$ is given in Figure 12, where $F$ is the net foundation shear load - that is, the total lateral load acting on the wind turbine due to wind, wave and current (this parameter can also be used for scaling the strain field produced by the vertical load, but owing to the complex nature of load distribution this was neglected). While plotting the data in Figure 11, the lower of the two peaks in the frequency domain was used, as this represents the first natural frequency of the structure (see Figure 10). Figure
11 shows the results of five tests carried out on dry fraction E sand in which up to 1.2 million cycles were imposed, and three tests carried on a mixture of fraction $\mathrm{B}$ and fraction $\mathrm{E}$ for the same period. The large gap in the results (between 0.5 million cycles and 1.05 million cycles) corresponds to a weekend break in recording results. The smaller interval in the data represents the overnight period when the snap-back test could not be conducted.

The test results suggest that the natural frequency of a wind turbine founded on suction caissons has the potential to change over time when it is subjected to cyclic loading. From the results obtained, the change in natural frequency follows a non-linear relationship, first increasing and later stabilising. The sand sample with a lower initial relative density (LED) showed a greater densification response; this is probably because it had a greater contraction potential. Following the initial increase in natural frequency, the latter apparent decrease could be attributed to the sand dilating in accordance with critical-state behaviour.

\section{Discussion and conclusion}

Offshore wind turbines are relatively new structures, the first one built in UK waters being at North Hoyle (2001). Very little is known about the long-term behaviour of these structures, but it has become apparent that soil-structure interaction is changing the dynamic behaviour of the structures over relatively short time spans. In an extreme case this could lead to the structure becoming unusable.

Considering these factors, the following conclusions can be drawn from the experimental study.

(a) Offshore wind turbines are dynamically sensitive structures, because the natural frequency of the overall system is very close to the forcing frequencies. The choice of foundation type and design alters the overall system frequency. The soil foundation makes the wind turbine system more flexible than the turbine tower would otherwise be on its own.

(b) Tetrapod foundations, in comparison with monopile or monopod foundations, enhance the complexity of the dynamic response of the overall system. This increased complexity is due to the width of the dynamically critical zone and the existence of two response peaks, a result of the

\begin{tabular}{lcccc}
\hline $\begin{array}{l}\text { Number of } \\
\text { cycles, } N\end{array}$ & $\begin{array}{c}\text { Measured lateral } \\
\text { foundation stiffness, } K_{l}: \\
\mathrm{N} / \mathrm{mm}\end{array}$ & $\begin{array}{c}\text { Predicted change in } \\
\text { frequency based on } \\
\text { Figure 6: \% }\end{array}$ & $\begin{array}{c}\text { Observed change in } \\
\text { frequency of system: \% } \\
\text { (see Figure 5) }\end{array}$ & $\begin{array}{c}\text { Near-field strain } \\
\text { level, } P / G D^{2}\end{array}$ \\
\hline 1 (Initial cycle) & 30.12 & 0.0 & 0.0 & $3.4 \times 10^{-3}$ \\
5000 & 11.06 & -37.0 & -4.0 & $3.4 \times 10^{-3}$ \\
10000 & 5.95 & -55.0 & -30.0 & $3.4 \times 10^{-3}$
\end{tabular}

Table 4. Observed frequency of system and predicted change in

frequency based on foundation-only degradation model 
Dynamics of offshore wind turbines

supported on two foundations

Bhattacharya, Cox, Lombardi and Muir Wood

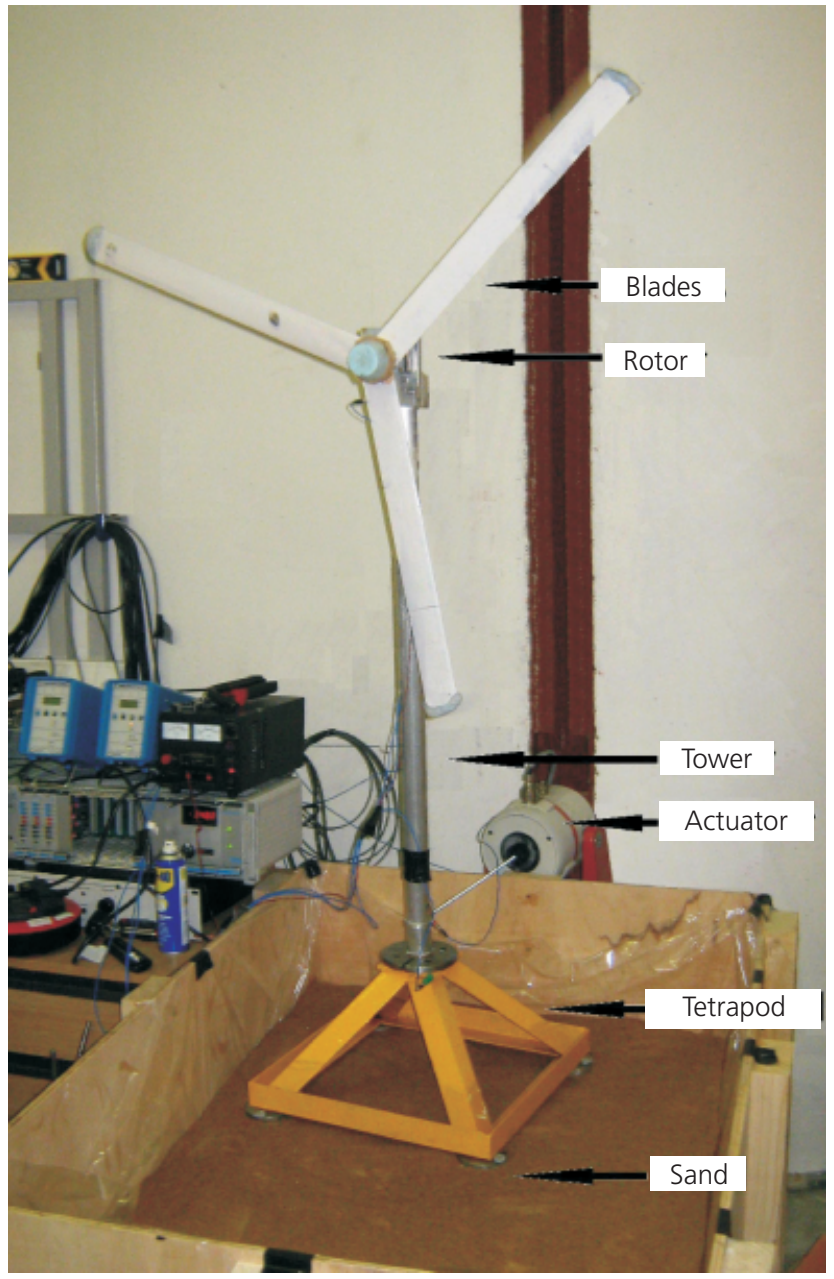

(a)

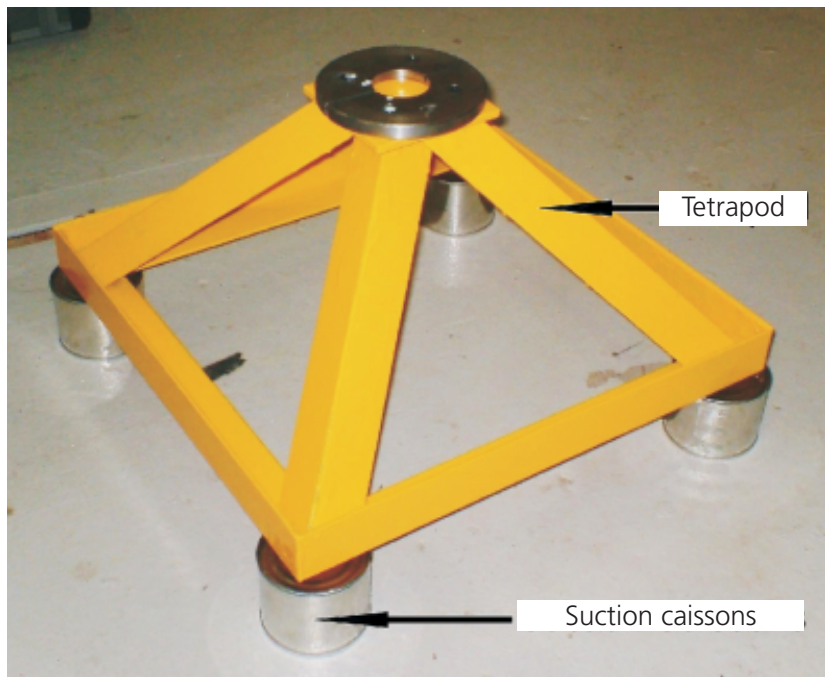

(b)

Figure 8. (a) Experimental set-up of 1:100 scale model of suction caissons; (b) details of foundation

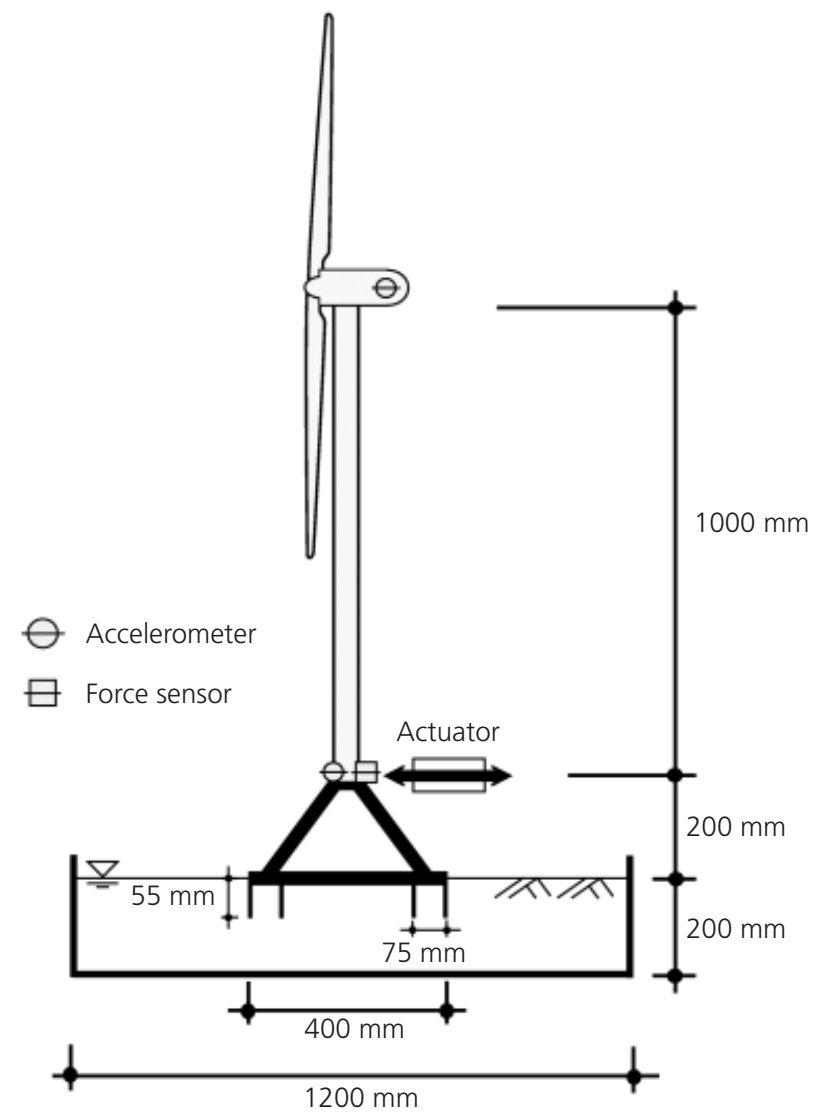

Figure 9. Schematic diagram of tetrapod set-up

\begin{tabular}{cc}
\multicolumn{3}{c}{ Sand type } \\
\hline $\begin{array}{c}\text { Leighton Buzzard } \\
\text { fraction E }\end{array}$ & $\begin{array}{c}\text { Mixture of Leighton } \\
\text { Buzzard fraction B } \\
\text { and fraction E }\end{array}$ \\
\hline LED & LBED \\
100 & 15 \\
0 & 85 \\
2.647 & 2.647 \\
32 & \\
0.613 & - \\
1.014 & 0.289 \\
\end{tabular}

Test ID

$\%$ LB fraction $E$

$\%$ LB fraction $B$

Specific gravity of solids, $G_{s}$

$\begin{array}{lcc}\psi_{\text {crit }} & 32 & - \\ e_{\min } & 0.613 & 0.289 \\ e_{\max } & 1.014 & 0.614\end{array}$

Table 5. Experimental sand properties used in suction caisson tests

variation of the vertical support stiffness of the individual caissons.

(c) The frequency of the system can change with the number of loading cycles, owing to changes in foundation stiffness. This change depends on the type of soil and the nature of the foundation. The change in frequency of the overall system cannot be predicted from the degradation of foundation 


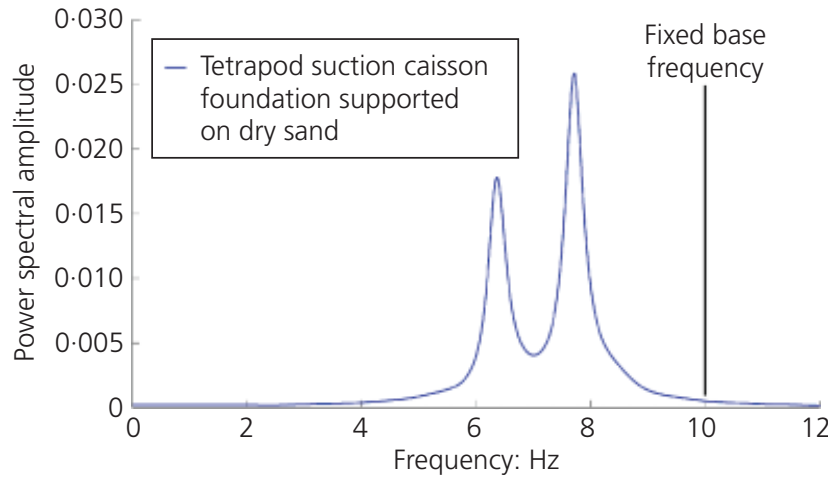

Figure 10. Typical test result from snap-back test on wind turbine supported on suction caisson, plotted in frequency domain

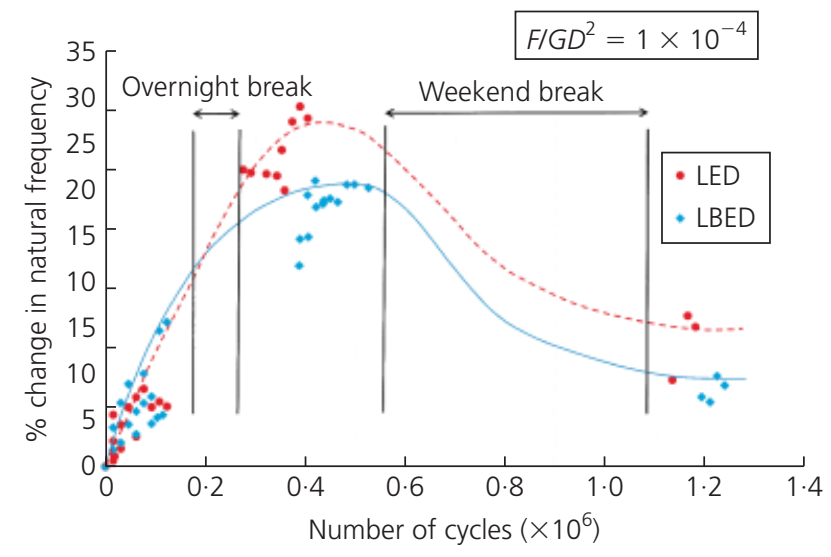

Figure 11. Long-term suction caisson results

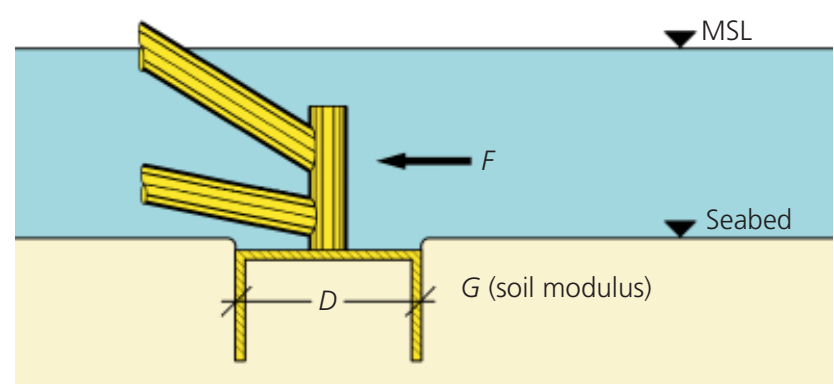

Figure 12. Definition of $F / G D^{2}$ used for data analysis of suction caissons

stiffness alone. The results thus present an intriguing challenge for the future design of offshore wind turbines, if the observations made in these scale model tests are replicated in operational prototype systems. Any change of the dynamic properties of a wind turbine will only increase the sensitivity of such a system, limiting the range of safe operation of such structures. Further research is required to understand more clearly the long-term performance of offshore wind turbines.

\section{Acknowledgements}

The contributions to the project from Dr David Nash and Professor Colin Taylor are duly noted. The work presented in this paper is part of the ongoing research into dynamic stability of offshore wind turbines being conducted at the University of Bristol.

\section{REFERENCES}

Adhikari S and Bhattacharya S (2011) Vibrations of windturbines considering soil-structure interaction. Wind and Structures 14(2): 85-112.

Adhikari S and Bhattacharya S (2012) Dynamic analysis of wind turbine towers on flexible foundations. Shock and Vibration, 19(1): 37-57.

Andersen OJ and Løvseth J (2006) The Frøya database and maritime boundary layer wind description. Marine Structures 19(23): 173-192.

Bhattacharya S, Lombardi D and Muir Wood D (2011) Similitude relationship for physical modelling of monopile-supported wind turbines. International Journal of Physical Modelling in Geotechnics 11(2): 58-68.

Bladed (2008) Wind Turbine Design Software. GL Garrad Hassan, Glasgow, UK.

Bye A, Erbrich C, Rognlien B and Tjelta TI (1995) Geotechnical design of bucket foundations. Proceedings of Offshore Technology Conference, Houston, TX, USA, OTC 7793.

Byrne BW and Houlsby GT (2003) Foundations for offshore wind turbines. Philosophical Transactions: Mathematical, Physical and Engineering Sciences 361(1813): 2909-2930.

Carter J (2007) North Hoyle offshore wind farm: design and build. Proceedings of the Institution of Civil Engineers Energy 160(1): 21-29.

Dihoru L, Taylor CA, Bhattacharya S et al. (2010) Stiffness design for granular materials: theoretical and experimental considerations. Proceedings of the 7th International Conference on Physical Modelling in Geotechnics (Springman SM, Laue J and Seward L (eds)). CRC Press, London, UK, pp. 129-134.

German R (1989) Particle Packing Characteristics. Metal Powder Industries Federation, Princeton, NJ, USA.

Hardin BO and Drnevich VP (1972) Shear modulus and damping in soils: design equations and curves. Journal of the Soil Mechanics and Foundations Division, ASCE 98(7): 667-692.

Houlsby GT, Ibsen LB and Byrne B (2005) Suction caisson for wind turbines. Proceedings of Frontiers in Offshore Geotechnics, ISFOG 2005 (Gourvenec S and Cassidy MJ (eds)). Taylor \& Francis, London, UK, pp. 359-366.

Ibsen LB and Brincker R (2004) Design of a new foundation for offshore wind turbines. Proceedings of the 22nd International Modal Analysis Conference (IMAC XXII), Detroit, MI, USA.

Kühn M (2000) Dynamics of Offshore Wind Energy Converters on Monopile Foundations: Experience from the Lely Offshore Wind Farm. Engineering and Physical Sciences Research Council, Didcot, UK, EPSRC Workshop Report on OWEN (Offshore Wind Energy Network). 
Leblanc C, Byrne BW and Houlsby GT (2010) Response of stiff piles to random two-way lateral loading. Géotechnique 60(9): $715-721$.

Pierson WJ and Moskowitz L (1964) A proposed spectral form for fully developed wind seas based on the similarity theory of SA Kitaigordskii. Journal of Geophysical Research 69(24): 5181-5190.
Welch PD (1967) The use of fast Fourier transform for the estimation of power spectra: a method based on time averaging over short modified periodograms. IEEE Transactions on Audio and Electroacoustics 15(2): 70-73.

Zaaijer MB (2006) Foundation modelling to assess dynamic behaviour of offshore wind turbines. Applied Ocean Research 28(1): $45-57$.

\section{WHAT DO YOU THINK?}

To discuss this paper, please email up to 500 words to the editor at journals@ice.org.uk. Your contribution will be forwarded to the author(s) for a reply and, if considered appropriate by the editorial panel, will be published as a discussion in a future issue of the journal.

Proceedings journals rely entirely on contributions sent in by civil engineering professionals, academics and students. Papers should be 2000-5000 words long (briefing papers should be 1000-2000 words long), with adequate illustrations and references. You can submit your paper online via www.icevirtuallibrary.com/content/journals, where you will also find detailed author guidelines. 